\title{
Calcified cavitating mesenteric lymph node syndrome: Case presentation and literature review
}

\author{
Dipinder S Keer MS BBA ${ }^{1}$, Paul Jeon MD FRCPC ${ }^{2}$, Mark R Borgaonkar MD FRCPC ${ }^{3}$, Stefan Potoczny MD²
}

\begin{abstract}
DS Keer, P Jeon, MR Borgaonkar, S Potoczny. Calcified cavitating mesenteric lymph node syndrome: Case presentation and literature review. Can J Gastroenterol 2010;24(6):355-358.
\end{abstract}

Cavitating mesenteric lymph node syndrome (CMLNS) is a rare complication of celiac disease. Globally, only 36 cases of CMLNS have been reported to date. The present article reports an incidence of its unique pathology and possible complications of celiac disease, followed by a review of the syndrome. A case involving a 51-year-old man with celiac disease who was referred to hospital because of a nontender abdominal mass is described. Plain film $\mathrm{x}$-ray of the abdomen revealed fine curvilinear calcifications in the left lower quadrant. A complex, cystic-appearing, lobulated mass with somewhat echogenic walls most consistent with calcifications was revealed on subsequent ultrasound (US) imaging. Colour Doppler imaging showed no evidence of vascularity within the lesion. Computed tomography (CT) imaging showed a thin rim of calcification in the walls of multiple cystic components. Enhanced magnetic resonance (MR) imaging revealed a mixed solid and cystic multiloculated mass, with fat-fluid layers originating from the root of the small bowel mesentery. A CT-guided biopsy was performed. The fine-needle aspirate revealed calcified matter with no associated cellular material. No malignant cells were seen; CMLNS was established as the diagnosis. To the authors' knowledge, there are no previous reports in the literature describing the finding of rim calcification on US or MR imaging in the setting of CMLNS. CMLNS is an important diagnosis to consider, particularly in patients with a history of celiac disease. The finding of rim calcification on US in the setting of cavitating mesenteric adenopathy should prompt further diagnostic imaging studies such as CT or MR imaging. These may lead to additional pathology studies such as a CT-guided biopsy to further characterize the lesion at the cellular level, to investigate potential malignancy and to further guide follow-up and patient management.

Key Words: Calcification; Cavitating; Celiac; CT; Lymph node; MR; US

Celiac disease is a malabsorption syndrome in which dietary gluten damages the small bowel mucosa. Gluten contains gliadin - the primary toxic component - found in wheat, barley and rye products. The differential diagnosis for the clinical and radiological presentation of suspected celiac disease includes viral enteritis, giardiasis, Crohn's disease, AIDS and Whipple's disease (1). The gold standard diagnostic test for celiac disease is small bowel biopsy demonstrating villous atrophy, which improves after a period of gluten-free diet. Positive serology, such as antiendomysial or antitissue transglutaminase antibodies, may also establish the diagnosis (2). Complications

\section{La cavitation ganglionnaire mésentérique calcifiée : Présentation de cas et analyse bibliographique}

La cavitation ganglionnaire mésentérique (CGM) est une rare complication de la maladie cœliaque. Dans le monde, seulement 36 cas de CGM ont été déclarés jusqu'à maintenant. Le présent article rend compte d'une incidence de cette pathologie unique et des complications possibles de la maladie cœliaque et expose une analyse de ce syndrome. Les auteurs décrivent le cas d'un homme de 51 ans ayant une maladie cœliaque qui a été aiguillé vers un hôpital en raison d'une masse abdominale indolore. Une masse lobulée complexe d'apparence kystique aux parois quelque peu échogènes compatibles avec des calcifications a été révélée à l'échographie (EG). Une radiographie sans préparation de l'abdomen a révélé de fines calcifications curvilinéaires du quadrant inférieur gauche, tandis que l'imagerie Doppler couleur n'a démontré aucune trace de vascularité dans la lésion. La tomodensitométrie a dévoilé de fines croûtes de calcification dans les parois de multiples éléments kystiques. L'imagerie par résonance magnétique améliorée a révélé une calcification périphérique autour d'une masse mixte solide et kystique multiloculée, comportant des couches de liquide gras en provenance de la racine du mésentère de l'intestin grêle. Une biopsie par tomodensitométrie a été effectuée. L'aspirat à l'aiguille a permis de déceler des matières calcifiées sans matières cellulaires connexes. On n'a observé aucune cellule maligne, et on a diagnostiqué une CGM. À la connaissance des auteurs, aucune publication ne présente de compte rendu de calcification périphérique dépisté par imagerie par résonance magnétique ou par EG en présence d'une CGM. La CGM est un diagnostic important à envisager, notamment chez les patients ayant des antécédents de maladie cœeliaque. L'observation de calcification périphérique à l'EG en cas d'adénopathie de la cavitation mésentérique devrait susciter de nouvelles études d'imagerie diagnostique, telles que la tomodensitométrie ou l'imagerie par résonance magnétique. Les résultats pouvaient susciter d'autres études pathologiques, telles que la biopsie par tomodensitométrie, afin de mieux caractériser la lésion au niveau cellulaire, afin d'explorer la possibilité de malignité et de mieux orienter le suivi et la prise en charge du patient.

${ }^{1}$ Faculty of Medicine; ${ }^{2}$ Department of Radiology; ${ }^{3}$ Division of Gastroenterology, Department of Medicine, Memorial University of Newfoundland, St John's, Newfoundland

Correspondence: Mr Dipinder S Keer, Faculty of Medicine, Memorial University of Newfoundland, 300 Prince Phillip Drive, St John's,

Newfoundland A1B 3V6. Telephone 709-777-6690, fax 709-777-8296, e-mail dipinder.keer@munmed.ca

Received for publication December 5, 2009. Accepted December 7, 2009 


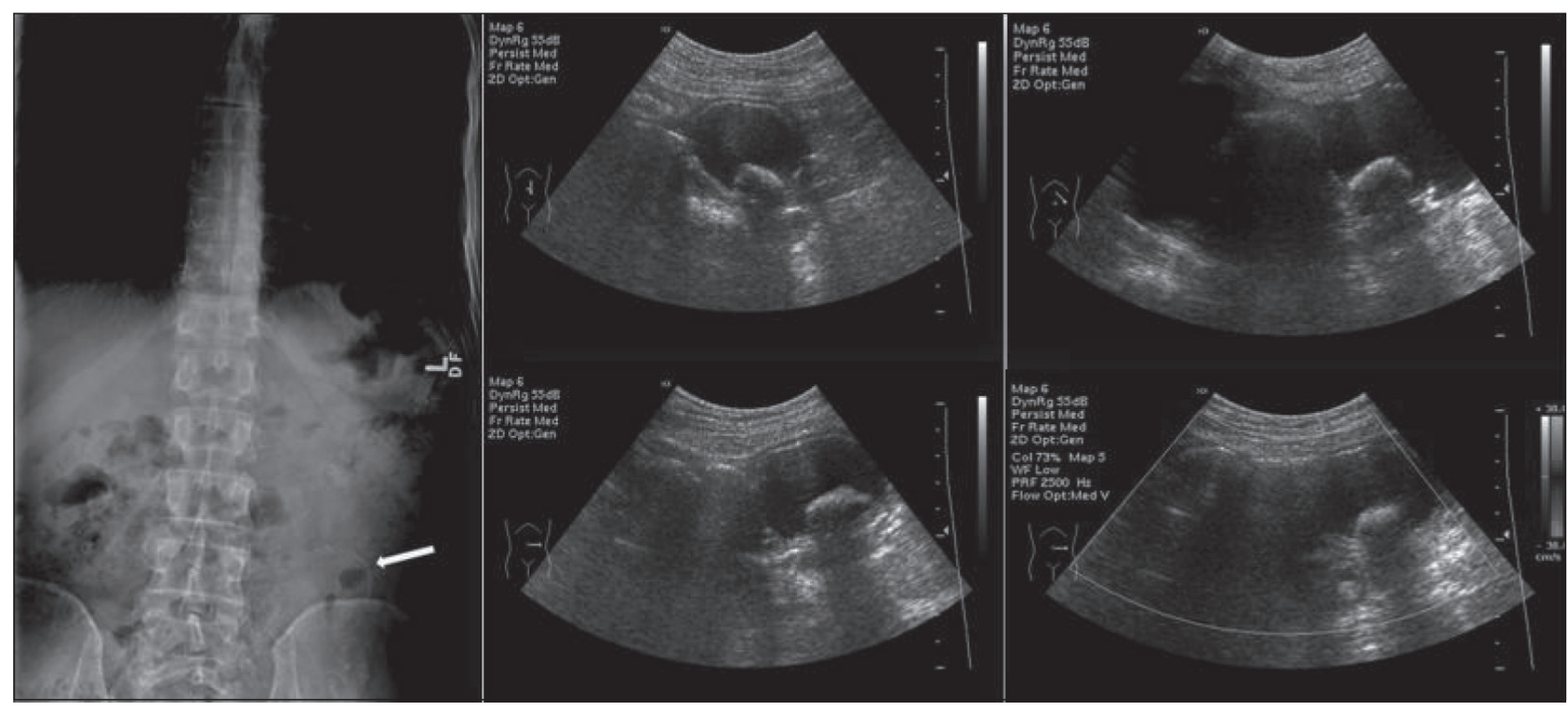

Figure 1) Left panel Plain film $x$-ray of the abdomen revealed fine curvilinear calcifications in the left lower quadrant (arrow). Middle and right panels A complex cystic-appearing, lobulated mass measuring $10.5 \mathrm{~cm}$ at its greatest diameter with somewhat echogenic walls with posterior shadowing consistent with calcifications was seen on ultrasound imaging. Colour Doppler imaging showed no evidence of vascularity within the lesion

association with hyposplenism, which may be evident on peripheral blood smear along with target cells and Howell-Jolly bodies $(3,4)$. At laparotomy or autopsy, multiple cystic masses containing milky, creamy fluid are observed in the jejunoileal mesentery. Microscopic examination of these masses reveals cavitated, atrophic lymph nodes without evidence of malignancy or infection. Central acidophilic, lipid-containing fluid is surrounded by a rim of remnant lymph node tissue composed of follicles, sinuses and capsular fragments (3-5). These lymph node changes are always confined to the mesenteric nodal chain.

\section{CASE PRESENTATION}

An otherwise healthy 51 -year-old man with a history of celiac disease and no constitutional symptoms presented with a nontender, left lower quadrant abdominal mass.

Plain film $x$-ray of the abdomen revealed fine curvilinear calcifications in the left lower quadrant. Ultrasound (US) imaging revealed a complex, cystic-appearing lobulated mass with somewhat echogenic walls, with posterior shadowing most consistent with calcifications. The mass was located in the midline at the level of the umbilicus, extending to the left lower quadrant (Figure 1). The mass measured $10.5 \mathrm{~cm}$ at its greatest diameter. Computed tomography (CT) imaging confirmed this mass to be a laminated, multicystic complex lesion measuring $11.6 \mathrm{~cm} \times 6.9 \mathrm{~cm} \times 12 \mathrm{~cm}$, originating from the root of the small bowel mesentery (Figure 2). A thin rim of calcification was seen in the walls of the multiple cystic components. A standard magnetic resonance (MR) imaging evaluation of the abdomen was performed (Figure 3). Various areas of increased T2 signal were seen throughout the multiloculated mass that corresponded to low T1 signal on the T1-weighted images, consistent with a cystic component to this mass. However, the in-and-out of phase imaging showed regions of signal dropout, particularly in the anterior cystic component, which measured $4.3 \mathrm{~cm} \times 3.7 \mathrm{~cm}$. This suggested the presence of fat within the anterior portion of the lesion. A second area of signal drop-out was also seen on the in-and-out of phase images that was a slightly more hyperintense focus measuring $8 \mathrm{~mm}$ in size within the substance of the mass - this was also consistent with the presence of fat. More cellular components were seen layered along the dependent cystic portions of the mass. These areas did not show any appreciable enhancement after gadolinium administration.

As noted previously, there was no appreciable enhancement of the cellular components of the multilobulated, predominantly cystic lesion. There was questionable wall enhancement of one of the larger cystic components along the left lateral border. Evaluation of the liver showed a small $8 \mathrm{~mm}$ hepatic cyst, with no other suspect intrahepatic lesions visible. There was cholelithiasis, but no evidence of duct dilation. The pancreas, adrenals and kidneys were normal. The spleen was small, measuring $7.2 \mathrm{~cm}$ in size.

The most likely diagnosis, given the patient's history of celiac disease, was CMLNS. A somewhat atypical feature was the presence of rim calcification, which was visible on a previous CT examination. Other less likely considerations included Whipple's disease and mycobacterial infection. The presence of lipid within the lesions diminished the possibility of other mesenteric considerations such as lymphoma or necrotic metastatic disease.

A CT-guided biopsy was performed. This was a difficult biopsy due to the solid component of the mass as well as its texture. As a result, it was deemed unsafe to perform a core biopsy in this patient and only fine-needle aspirations were performed. The patient tolerated the procedure well, with no complications. The fine-needle aspirate revealed calcified matter with no associated cellular material. No malignant cells were visible. A decision was made for conservative management and close follow-up.

\section{DISCUSSION}

Cavitation of mesenteric lymph nodes as a complication of celiac disease was described originally by Hemet et al (2) in 1969. In the literature, the association was suggested by Jones 


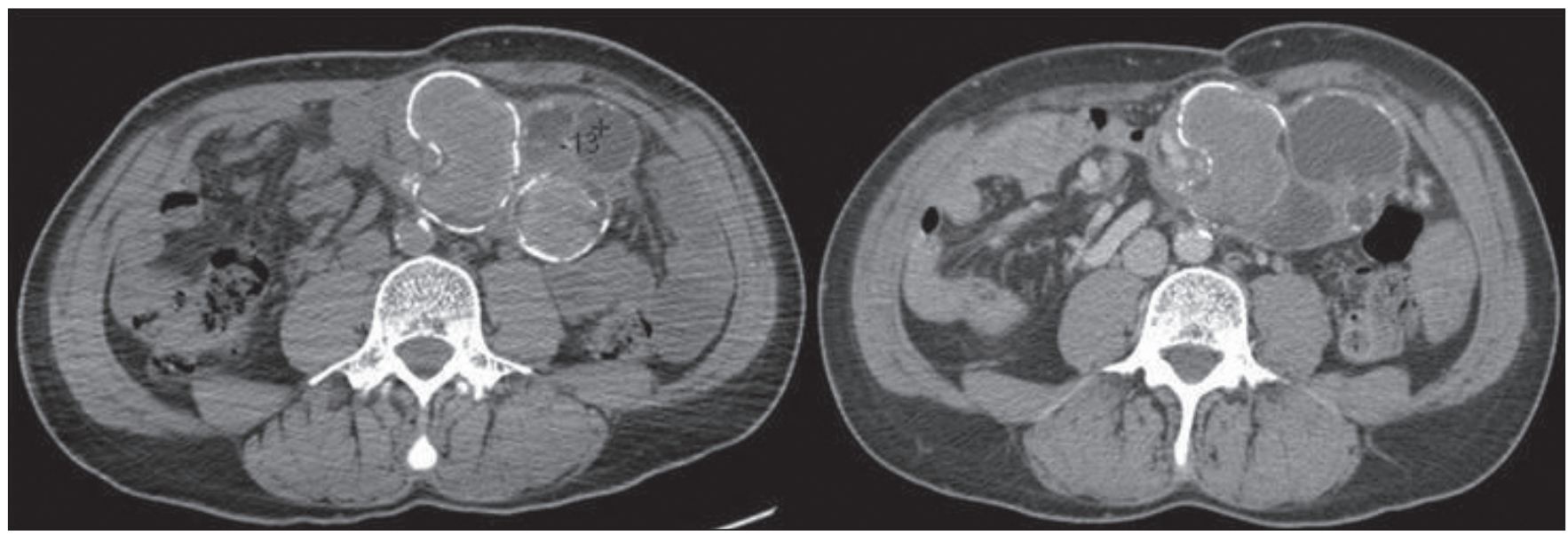

Figure 2) Computed tomography imaging confirmed the mass to be a laminated, multicystic complex lesion measuring $11.6 \mathrm{~cm} \times 6.9 \mathrm{~cm} \times 12 \mathrm{~cm}$, originating from the root of the small bowel mesentery. A thin rim of calcification was seen in the walls of the multiple cystic components

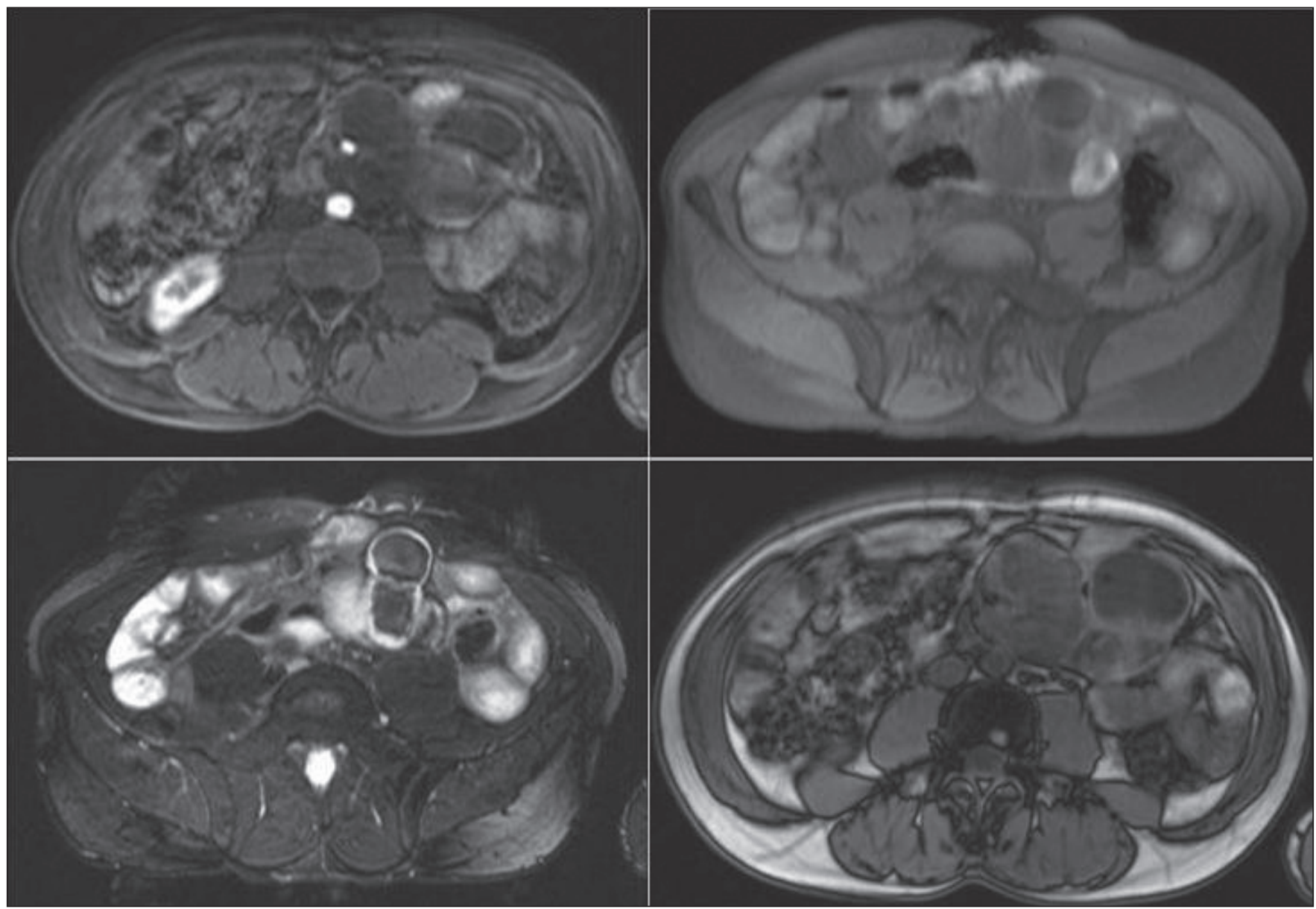

Figure 3) A standard magnetic resonance imaging evaluation of the abdomen was performed. Various areas of increased T2 signal were seen throughout the multiloculated mass that corresponded to low T1 signal on the T1-weighted images, consistent with a cystic component to this mass

and Gleeson (6) in 1973. Since the analyses by Howat et al (7) and Schmitz et al (8), nine additional reports of CMLNS have been reported from Spain $(9,10)$, France (11), the Unites States (12-15), Germany (8), Belgium (16), Saudi Arabia (17) and India (18), bringing the total number of cases reported, including the case presented herein, to 37 . The mortality from this complication is as high as $50 \%$, and is usually associated with sepsis or hemorrhage. It is commonly associated with hyposplenism, and Howell-Jolly bodies may be detected on blood film analysis (8). The pathogenesis of CMLNS, although unknown, has been associated with excessive antigenic exposure of the immune system via a damaged intestinal mucosa, leading to depletion of cellular lymphoid elements in mesenteric lymph nodes and spleen, causing a cystic change or 'cavitation' in some patients with celiac disease. An alternative hypothesis is the necrosis of the mesenteric lymph nodes triggered by localized immune-mediated complement activation and intravascular coagulation (13). The differential diagnosis for this type of 
adenopathy includes lymphoma or mycobacterial infection. A helpful differentiating feature to note is that in lymphoma the adenopathy is unlikely to be restricted to the mesenteric lymph nodes (1). An intra-abdominal cystic lymphangioma may also mimick mesenteric lymph node cavitation (19).

Typical CT and US findings of CMLNS have been described. Reported masses have measured $2 \mathrm{~cm}$ to $8 \mathrm{~cm}$ in diameter. On CT, these cystic mesenteric masses have central low attenuation, with thin enhancing rims. The central material may be fluid or fat attenuated $(12,14,20)$. Fat-fluid levels within the masses may be apparent on CT (14). Sonographically, mesenteric masses appear as anechoic cysts $(12,21,22)$. Atrophy of the spleen may be evident. Percutaneous image-guided diagnostic aspiration of these cysts has been described previously $(12,22)$. Lowattenuation adenopathy on CT can also be seen in instances of mycobacterial infection, Whipple's disease, lymphoma and some necrotic metastases such as germ cell tumours. However, fat-fluid levels on CT are believed to be unique to the cavitated mesenteric adenopathy associated with celiac disease (13). MR imaging findings have been found to be helpful in making a specific diagnosis, thus obviating further diagnostic intervention such as image-guided biopsy. Both T2- and T1-weighted axial imaging have been used to show a fat-fluid layer within the cysts. Signal loss due to chemical shift artefact was also found to be apparent at the fat-fluid interface on out-of-phase spoiled gradient-recalled acquisitions in the steady state. Fat-fluid levels were not found to be readily apparent on CT (13).

We are not aware of any previous reports in the literature describing the finding of rim calcification on US or MR imaging

\section{REFERENCES}

1. Buckley O, Brien JO, Ward E, Doody O, Govender P, Torreggiani WC. The imaging of coeliac disease and its complications. Eur J Radiol 2008;65:483-90.

2. Hemet J, Bourquelot R, Colin R. Malabsorption et cavitation mesenterique. Arch Anat Path 1969;17:A115-8. (Abst)

3. Not T, Horvath K, Hill ID, et al. Celiac disease risk in the USA: High prevalence of antiendomysium antibodies in healthy blood donors. Scand J Gastroenterol 1998;33:494-8.

4. Catassi C, Ratsch IM, Fabiani E, et al. Coeliac disease in the year 2000: Exploring the iceberg. Lancet 1994;343:200-3.

5. MacDonald WC, Dobbins WO, Rubin CE. Studies on the familial nature of celiac sprue using biopsy of the small intestine. N Engl J Med 1968;272:448-56.

6. Jones PE, Gleeson MH. Mucosal ulceration and mesenteric lymphadenopathy in coeliac disease. BMJ 1973;3:212-3.

7. Howat AJ, McPhie JL, Smith DA, et al. Cavitation of mesenteric lymph nodes: A rare complication of coeliac disease associated with a poor outcome. Histopatholology 1995;27:349-54.

8. Schmitz F, Herzig KH, Tiemann M, Reinecke-Luthge A, Nitsche R, Folsch UR. On the pathogenesis and clinical course of mesenteric lymph node cavitation and hyposplenism in coeliac disease. Int J Colorectal Dis 2002;17:192-8.

9. Susano R, de Quirós JF, Caminal L, Marroquín AG, Trapiella L, Astudillo A. [Mesenteric lymph node cavitation: A rare complication of celiac disease in the adult]. Gastroenterol Hepatol 1998;21:84-7.

10. Méndez-Uriburu L, Ahualli J, Fajre L, Ortiz Mayor M. [Cavitating mesenteric lymph node syndrome]. Radiologia 2006;48:241-4.

11. Arotçarena R, Hammel P, Terris B, Guth A, Bernades P, Ruszniewski P. [Regression of mesenteric lymph node cavitation syndrome complicating celiac disease after a gluten free diet.] Gastroenterol Clin Biol 2000;24:579-81.

12. Huppert BJ, Farrell MA. Case 60: Cavitating lymph node syndrome. Radiology 2003;228:180-4. in the setting of cavitating mesenteric adenopathy. de Vries et al (23) reported a case in which a cystic tumour of the mesentery that measured $13 \mathrm{~cm}$ in size and consisted of multiple egg-like structures with a calcified shell and fatty necrotic content was visualized on CT. Microscopy showed variably necrotic tissue with hematin pigment inside and lymph node remnants outside of the tumour, compatible with lymph node cavitation.

The prevalence of celiac disease has been reported to be as high as one in 100 to one in 500 individuals (3-5). Radiological investigations such as barium studies and cross-sectional imaging have been helpful in suggesting celiac disease as part of a differential diagnosis, especially because patients often present late and are initially evaluated with cross-sectional imaging in a workup for weight loss or nonspecific gastrointestinal symptoms (1). Imaging in these cases may not only suggest a diagnosis of celiac disease but, more importantly, demonstrate and evaluate potential complications such as malignancy or CMLNS. Expedient diagnosis is important to decrease the morbidity and mortality associated with untreated celiac disease (24).

Therefore, CMLNS is an important diagnosis to consider, particularly in patients with a history of celiac desease. The finding of rim calcification on US or MR imaging in the setting of cavitating mesenteric adenopathy should prompt further pathology studies such as a CT-guided biopsy to further characterize the lesion at the cellular level to investigate potential malignancy, and to guide further follow-up and patient management.

13. Huppert BJ, Farrell MA, Kawashima A, Murray JA. Diagnosis of cavitating mesenteric lymph node syndrome in celiac disease using MRI. AJR 2004;183:1375-7.

14. Reddy D, Salomon C, Demos TC, Cosar E. Mesenteric lymph node cavitation in celiac disease. AJR 2002;178:247

15. Keller CE, Gamboa ET, Hays AP, et al. Fatal CNS vasculopathy in a patient with refractory celiac disease and lymph node cavitation. Virchows Arch 2006;448:209-13.

16. Cornelis T, Hiele M, Vermeire S, Libbrecht L, Verslype C. A unique combination of celiac disease, mesenteric lymph node cavitation, splenic atrophy and necrotizing hepatitis. Acta Gastroenterol Belg 2008;71:267-70.

17. Tellisi N, Al-Omishy H. Cavitation of mesenteric lymph nodes without celiac disease. Saudi Med J 2004;25:1277.

18. Vibhuti, Vishal K, Gill A. Cavitatory mesenteric lymph node syndrome: A rare entity. Indian J Radiol Imaging 2010;20:66-8.

19. Miele L, Pierconti F, Forgione A, et al. Cystic lymphangioma of the mesentery and hyposplenism in celiac disease. Eur J Gastroenterol Hepatol 2007;19:1026-30.

20. Matuchansky C, Colin R, Hemet J, et al. Cavitation of mesenteric lymph nodes, splenic atrophy, and a flat small intestinal mucosa. Gastroenterology 1984;87;606-14.

21. Holmes GKT. Mesenteric lymph node cavitation in coeliac disease Gut 1986;27;728-33.

22. Burrell HC, Trescoli C, Chow K, Ward MJ. Case report: Mesenteric lymph node cavitation - an unusual complication of coeliac disease. Br J Radiol 1994;67:1139-40.

23. de Vries APJ, Bakker SJL, Kallenberg CGM, Gans ROB, Bongaerts AHH, Kluin PM. Cavitating lymph node syndrome. Neth J Med 2008;66:403-4.

24. Watson RGP. Diagnosis of coeliac disease. BMJ 2005;330:739-40. 


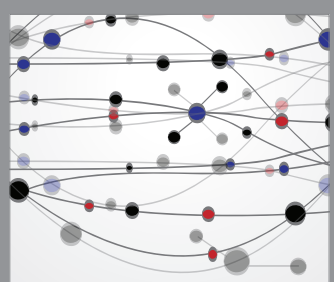

The Scientific World Journal
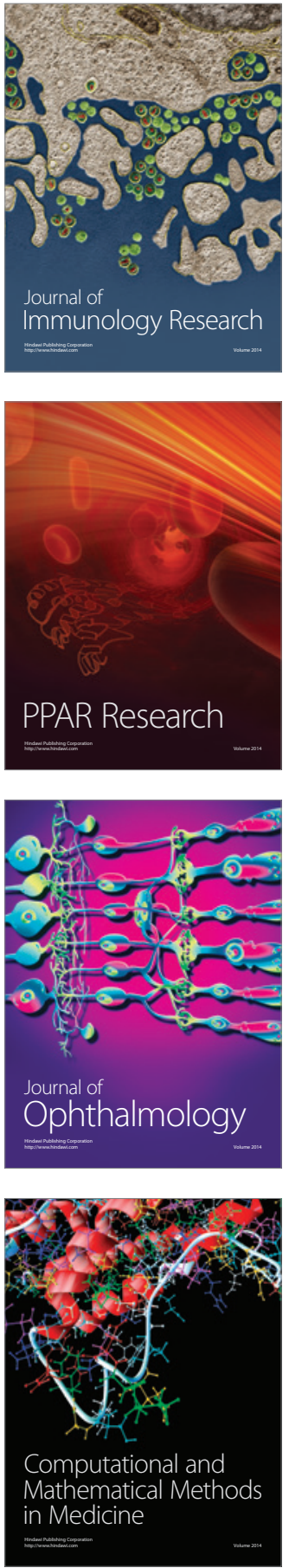

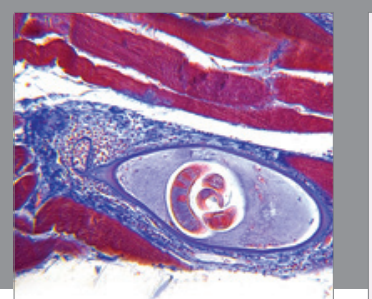

Gastroenterology Research and Practice

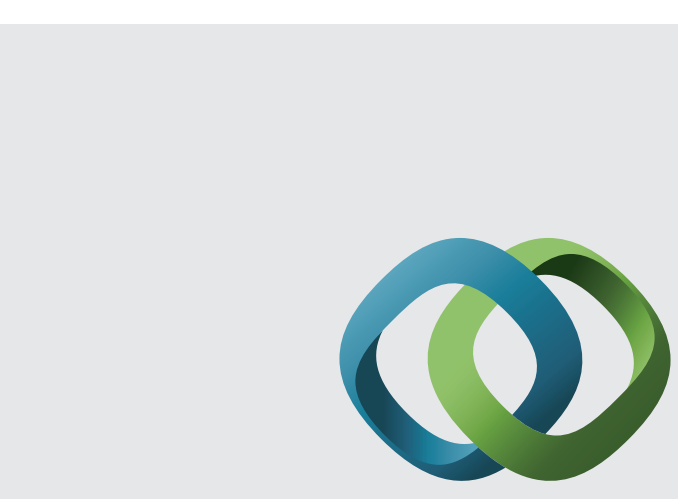

\section{Hindawi}

Submit your manuscripts at

http://www.hindawi.com
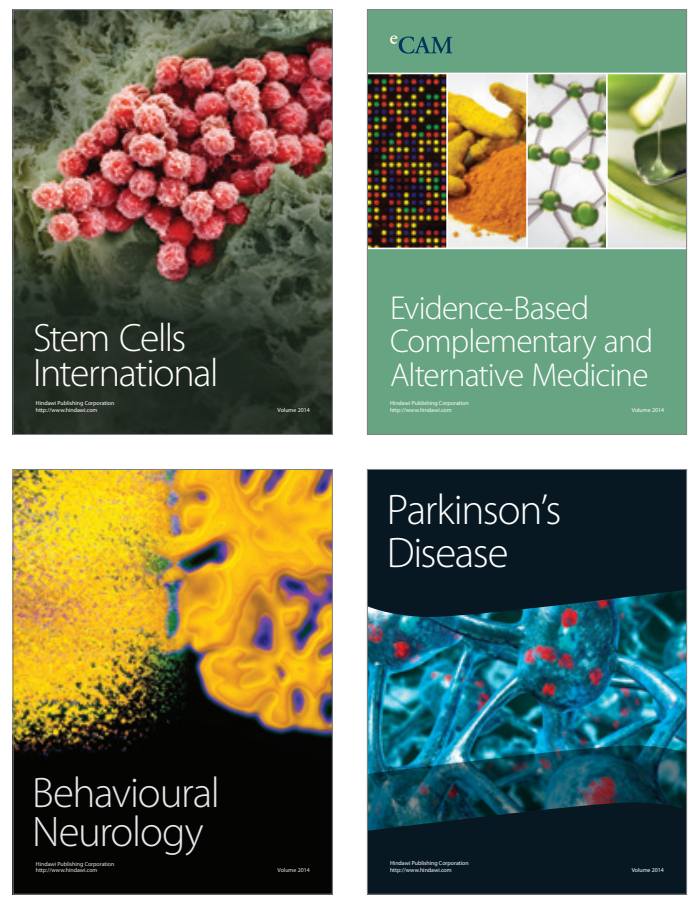
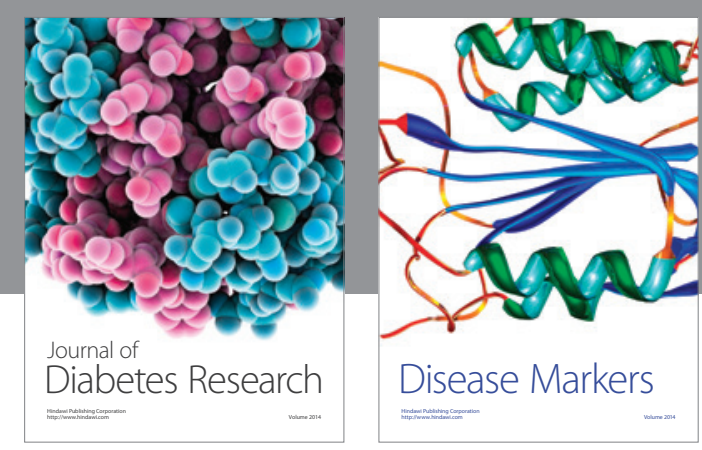

Disease Markers
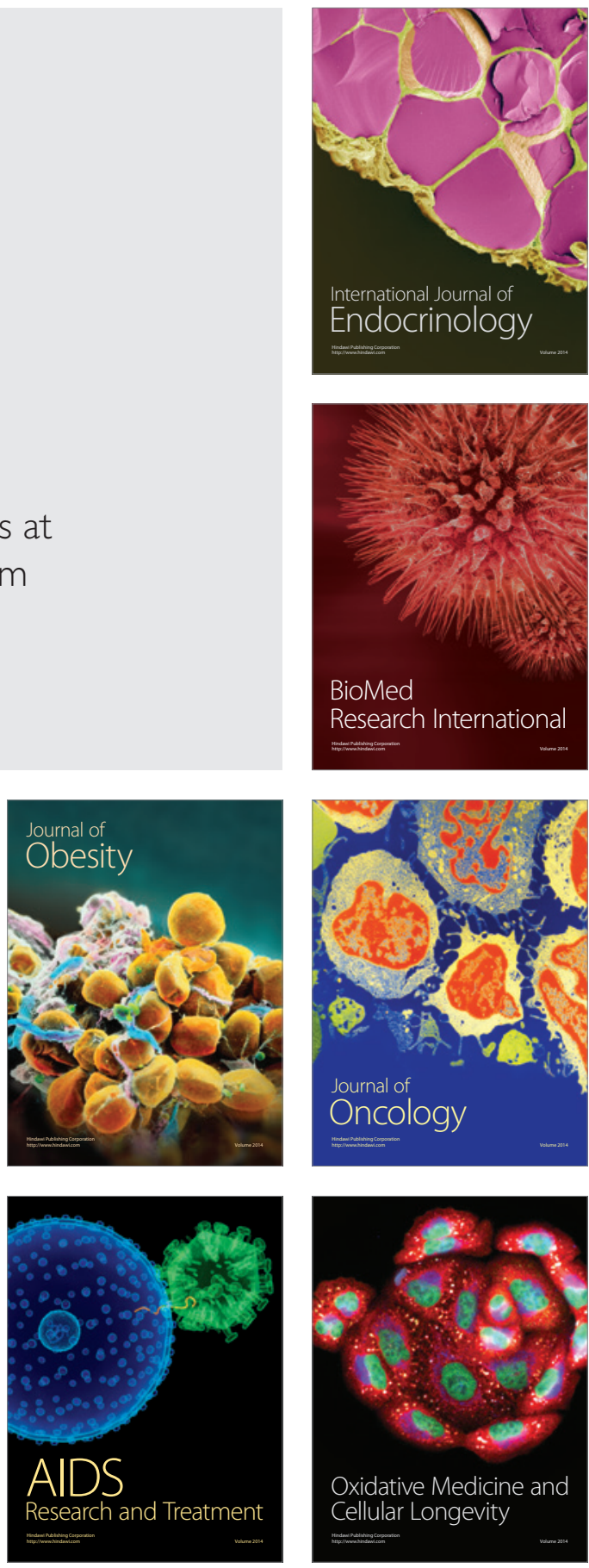